\title{
Current conservative management and classification of club foot: A review
}

\author{
Ganesan Balasankar ${ }^{\mathrm{a}}$, Luximon Ameersing ${ }^{\mathrm{b}, *}$ and Adel Al-Jumaily ${ }^{\mathrm{a}}$ \\ ${ }^{a}$ Department of FEIT, University of Technology Sydney, NSW, Australia \\ ${ }^{\mathrm{b}}$ The Hong Kong Polytechnic University, Hong Kong, China
}

Received 17 May 2016

Accepted 27 August 2016

Abstract. Clubfoot, known as congenital talipes equinovarus, is one of the complex paediatric foot deformity with the incidence of 1 in every 1000 live births. It consists of four complex foot abnormalities such as forefoot adductus, midfoot cavus, and hindfoot varus and ankle equinus. There are a number of surgical techniques (soft tissue releases, arthrodesis) used to correct clubfoot. However currently the conservative management (manipulation, serial casting, and braces) of clubfoot is considered as the best choice and it is widely accepted among orthopaedists. Clubfoot treated with surgical techniques might suffer various complications such as soft tissues contractures, neurovascular complications, infections, and shortening of the limbs. Although conservative method is generally considered as an effective method, it is still challenging to cure clubfoot in advance stages. Also, the classification of the initial severity of clubfoot is essential to evaluate the outcome of the treatment. In this review, the aim is to review the different types of conservative method and the assessment of clubfoot severity.

Keywords: Clubfoot conservative management, clubfoot, Ponseti method, Copenhagen method, French functional or physiotherapist method

\section{Introduction}

Congenital talipes equinovarus (CTEV) is a complex foot deformity in children that affects 150,000 200,000 newborn babies every year around the world and eighty percentages of clubfoot occurring in developing countries [1]. It is characterized by the following four structural deformities in foot and ankle: midfoot cavus, forefoot adductus, hindfoot varus, and ankle equinus - CAVE [2] (Fig. 1). The structural deformities of clubfoot might be caused by the subluxation of talocalcaneonavicular joint, dislocation of talus bone, abnormalities of peroneus and calf muscles, and contractures of soft tissues on the medial

${ }^{*}$ Corresponding author: Luximon Ameersing, The Hong Kong Polytechnic University, Hong Kong, China. Tel.: +852 27666449; E-mail: tcshyam@polyu.edu.hk. side of the foot [3-5]. Children with untreated clubfoot, also known as neglected clubfoot, will suffer in their daily life such as difficulties in gait pattern, mobility, daily living skills, and social activities. In addition, neglected clubfoot children walk on the dorsal side of the foot leading to complications such as callus formation, injuries, and infections on the dorsum of the foot [6]. For many years, there are a number of treatment methods either surgical or conservative procedures that have been proposed and debated to treat clubfoot. However, surgical methods have its own limitations due to post-surgical complications such as soft tissues contractures, neurovascular complications, infections, and shortening of the limbs. Recently, almost all of the orthopedicians agreed that the conservative treatment would be the best choice to correct the clubfoot. The goal of all conservative treatment methods is to obtain the plantigrade, pain-free 


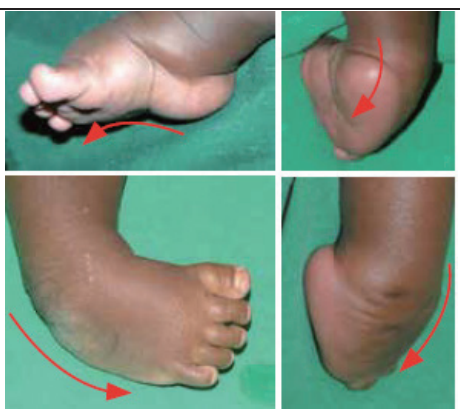

Fig. 1. Clubfoot (Source and approved by [67]).

and functional foot without any mobility problems [7]. Initially, around $400 \mathrm{BC}$, Hippocrates discussed about the manipulation and casting in a medical literature. In this literature, he suggested that management of clubfoot should be started as early as possible after the birth with manipulation method [8]. Subsequently, in 1782 , the first surgical procedure (subcutaneous tenotomy) was developed by Lorenz [9]. Followed by, in 1930s, Kite developed a gentle progressive manipulation and followed by plaster casting techniques. Then, in 1948, Ponseti developed his own method of manipulation and casting techniques after several years of observation of different conservative and surgical methods. It consists of weekly serial manipulations, casting, Achilles tendon tenotomy, and using foot abduction orthosis to avoid the recurrences of the clubfoot. Many of the researchers reported that Ponseti method achieved higher success rate than other conservative methods. Also, they reported that success rate of the conservative method for clubfoot is higher than surgical procedures [10-14]. Based on the literature review, many studies explain the use of Ponseti method more than other conservative methods. This study is an attempt to review the different types of conservative methods and its techniques, and the principles of those procedures for correction of clubfoot deformities. Also, this review tried to address the different method of classification and assessment of clubfoot.

\section{Prevalence of clubfoot}

The prevalence rate of clubfoot varies from 0.9 to 7 per 1000 live births in different populations [15-18]. The highest incidence of clubfoot occurs in the Polynesian population and lowest incidence in the Chinese population $[15,19,20]$. Most of the studies reported that the incidence of clubfoot is higher in male than in female (2:1), and this ratio is consistent in all ethnic population $[2,6,21-25]$. Fifty percentage of the cases are either bilateral or unilateral clubfoot, and the involvement of right foot is higher than unilateral clubfoot [24].

\subsection{Normal development of children foot}

A basic knowledge of lower extremity development is essential to understand the infant's foot. Lower limb buds appear at the $4^{\text {th }}$ weeks of the gestational period, and foot can be noted on the 4.5 weeks. At the 6 weeks, foot looks paddle shaped in an equinus and inverted position. Feet turns into equinus, and hindfoot, forefoot in a adducted position and notches is very clear between the toes during the 8 weeks. During $12^{\text {th }}$ weeks of the prenatal period, the foot rotates into supinated position. All digits are well developed in the period of the $9^{\text {th }}$ week, and $1^{\text {st }}$ and $5^{\text {th }}$ metatarsal head drop downward, and form the transverse arch of the foot. In addition, talus and calcaneus together are developing the subtalar joint. Moreover, tibia and fibula are articulated with the talus during this period. At the period between 13 to $16^{\text {th }}$ weeks, lower extremity increases in size, foot equinus level decreases, and foot will be in a perpendicular position to the lower leg. Finally, $28^{\text {th }}$ weeks, the foot will achieve the neutral position [26].

\subsection{Anatomy and biomechanics of the clubfoot}

Knowledge of foot anatomy and its biomechanics is helpful to identify and treat the foot deformities well. Biomechanically, clubfoot deformities occur due to abnormalities of the tarsal bones (talus, calcaneus, cuboid, and navicular), ligaments, joints, and atrophy of the calf muscles [27]. In the hindfoot region, due to the misalignment of the navicular, cuboid, calcaneus bone, it leads to medial displacement and inverted position in relation to the talus [28]. In addition to the medial displacement of bones, the hind foot turns into firm position, where the calcaneus and talus are in equines position; especially, head and neck of the talus is turned into severe planter flexion and medially displaced, and calcaneus medially rotated under the talus [29]. In some cases of clubfoot, the talus neck will be absent or shortened [30]. In the case of severe clubfoot deformity, the navicular bone will be displaced medially towards the head of the talus and it articulates with the medial side of the head of the talus [31-33]. Also, retraction and atrophy of calf muscles, the calcaneus bone will also be displaced into adducted and inverted position under the talus [13,34]. In the midfoot region, metatarsal joints are deformed and narrowed 


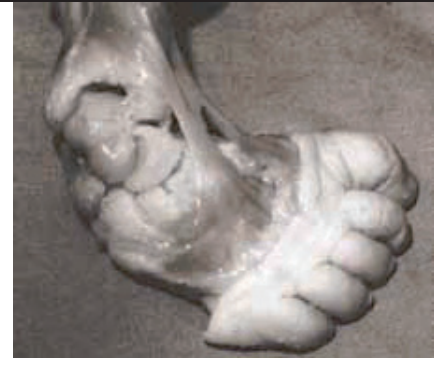

Fig. 2. Anatomical dissection of clubfoot (Source and thanks to [62]).

and in the forefoot region, the forefoot turns towards to the other side of the foot with a supinated position. It is referred as forefoot adduction and supinated position of the clubfoot. In relation to the hindfoot, it is in a more supinated position than forefoot; it develops a cavus deformity at the forefoot with medial and posterior skin crease [13]. Based on the literature review, one of the anatomical dissection studies shows that talus and calcaneus are displaced into medially and develops varus deformity in the hind foot (Fig. 2). Moreover, soft tissue contractures will also develop on the posterior, medial side of the ankle and sub-talar joint region of the foot, it leads to shortening of the medial and posterior tarsal ligaments, and medial displacement of the tibialis posterior, flexor hallus longus and flexor digitorum longus tendon occur. These contractures of the soft tissue structures limit the motion of the sub-talar joint $[13,33]$. Sometimes, there is a deficiency or absence of anterior tibial artery and dorsalis pedis artery in the clubfoot condition. One of the magnetic angiography studies revealed that diminished size of the peronial artery on the affected extremity of the leg [35].

\section{Etiology}

The causes of clubfoot are still not clearly known and it remains controversial. Previous studies have reported a number of theories to describe the causes of club foot. The causes of clubfoot are vascular, environmental, genetic, abnormal position in the utero, and anatomical factors [27]. Some of the studies have reported observed abnormalities in the intracellular structure of the muscles of the clubfoot [36]. Mostly clubfoot present as a birth defect (idiopathic congenital club foot), and around $20 \%$ of the clubfoot deformities are associated with other conditions such as arthrogryposis, myelodysplasia, Down syndrome,
Table 1

Dimeglio clubfoot classification

\begin{tabular}{ll}
\hline Classification & Types/Feautues \\
\hline Grade I & Benin: Reducible without any resistance \\
Grade II & $\begin{array}{l}\text { Moderate: Reducible with certial degree of } \\
\text { resistance }\end{array}$ \\
Grade III & Severe: Reducible with certial degree of resistance \\
Grade IV & Very severe: Not reducible
\end{tabular}

Larsen's Syndrome, freeman-Sheldon syndrome, and multiple congenital abnormalities [2,24,27,37]. Especially, club foot associated with distal arthrogryposis, meningomyelocele, and is considered a main etiological factor among the involvement of nervous system disorders [38]. In addition, the causes of clubfoot are also associated with some risk factors such as male gender, smoking during the maternal period, and diabetes on the maternal stage, maternal age, marital status, and parity [39].

\subsection{Classification of clubfoot}

Clubfoot can be classified into four types based on the causes and treatment responses: 1) Postural, 2) Idiopathic, 3) Neurogenic, 4) Syndromic. Generally, the postural clubfoot can be resolved by stretching and casting. Another type of clubfoot, called idiopathic clubfoot, is 'true' clubfoot and can be classified by various grades of severity. Neurogenic clubfoot is usually associated with neurological conditions such as spina bifida. Syndromic clubfoot are rigid type, and are associated with other anomalies [40]. Also, there are numbers of classification available to measure the severity of the clubfoot based on the physcial aspects of the clubfoot such as Pirani score and Dimeglio scale $[41,42]$. Dimeglio et al. introduced clubfoot classification in 1995, and it is classified into four types: Grade I-Grade IV [43-46]. In this method, four types of parameters, in a sagittal and horizontal plane, has been used to measure the clubfoot severity: Sagittal plane - 1) evaluation of equinus; 2) evaluation of varus; and horizontal plane - 3) evaluation of derotaion; 4) evaluation of forefoot adduction relative to the hindfoot. The each item of the scale starts from 0-4 points and maximum score is 20 points. It can also be graded as benign, moderate, severe, and very severe (Table 1 and Fig. 3). Another method of classification of clubfoot severity is, Pirani scoring system, which is commonly used to assess the severity, and progress of clubfoot treatment by Ponseti method. It is a simple scoring system based on the physical appearance of the foot, and it consist of 3 clinical signs in the hindfoot (three 

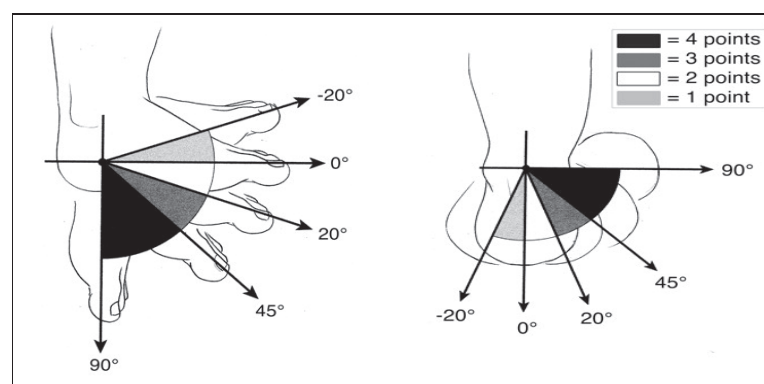

Equinus evaluation (Sagittal plane)

Varus evaluation (Sagittal plane)

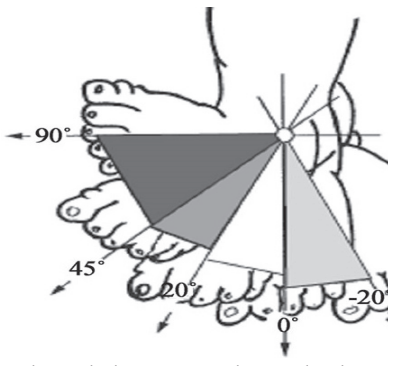

Horizontal plane: Derotation evaluation

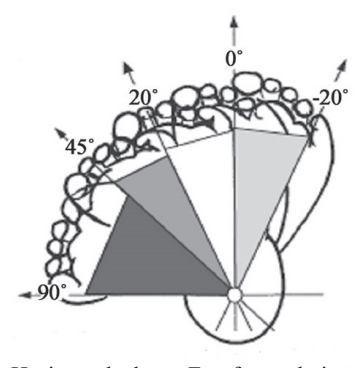

Horizontal plane: Forefoot relation with hindfoot

Fig. 3. Dimeglio et al. clubfoot classification system (Source and thanks to [63]).
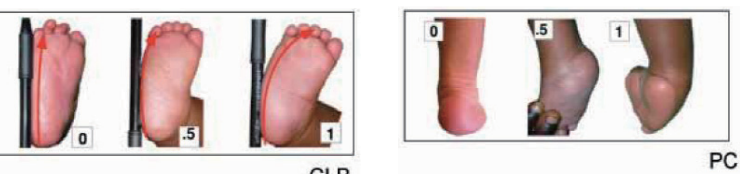

CLB
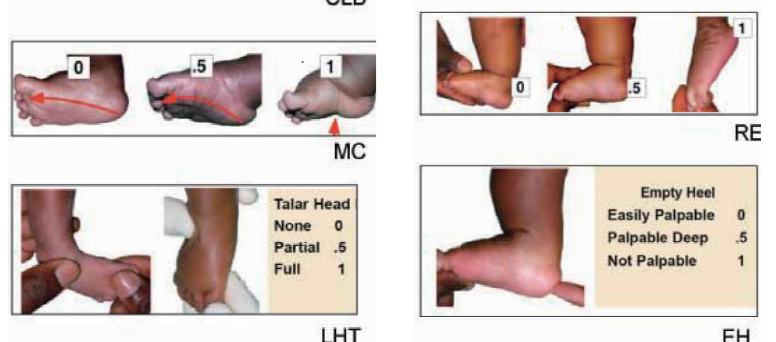

$\mathrm{EH}$

Fig. 4. Pirani Scoring system (Source and approved by [62]).

morphological changes sign: posterior crease, emptiness of the heel, rigid equinus) and 3 clinical signs in the midfoot (three morphological changes signs: lateral curvature of the foot, medial crease, position of the head of the talus on the lateral border (Fig. 4). The maximum score will be one for each item of the scale (0-normal, 0.5-mildly abnormal, 1-severe abnormal), and the total score is six [42].

\subsection{Management of clubfoot}

Clubfoot can be corrected by either conservative or surgical methods [46]. Historically, in $400 \mathrm{BC}$, the conservative management of clubfoot with manipulation and immobilization techniques was introduced by Hippocrates. Based on Hippocrates's principles of clubfoot management, there are number of conservative methods (Kite method, French method, Ponseti method - "manipulation, casting, tenotomy, foot abduction brace", other physical methods such as kinesio-therapy, thermo-therapy, electro-therapy, splinting, shoe modification and orthotic devices) developed recently to correct clubfoot $[6,47]$. In 1930s, at first, Dr. Kite developed a conservative method for treating clubfoot after facing poor results of surgical method $[48,49]$. In this method, the correction of clubfoot deformity components (adductus, varus, and equinus) was performed separately with progressive manipulation and serial casting [5,50]. Especially, correction of heel varus was performed by everting the calcaneus. In this method, when performing the manipulation, midfoot was used as fulcrum and pressure was applied on the calcaneo-cuboid joint (mid-tarsal joint area) to abduct the foot. The adducted deformity is corrected by foot abduction with applying pressure on the calcaneo-cuboid joint, and eversion of the hindfoot, which is done by casting or edges, used to correct the varus deformity of the foot. Finally, the equinus deformities will be corrected by progressive dorsiflexion of the foot after correction of other components [33]. In addition, night splint has been used to maintain the foot in dorsiflexion and mild abducted position to avoid the recurrences of the clubfoot. Initially, Kite reported that this method was successful in correcting the clubfoot however other researchers did not achieve the successful correction as mentioned by Dr. Kite [51,52]. In addition, one of the previous studies reported that approximately ninety percentages of the cases required surgical and soft releases in Kite's method [53,54]. Poor success rate of the Kite methods may be because of inaccurate method of manipulation, and below knee or short leg casting. Generally, short leg or below knee casting has disadvantages because it will not provide adequate position to maintain the corrected clubfoot $[6,54]$. At the same time, in this method, it will also make some complications due to inaccurate manipulation such as rocker bottom feet, subluxation of the navicular bone, rigidity of ligaments and capsule, torsion of the ankle (lateral side) and talar body [13].

Initially, the conservative management failed due to the poor understanding of functional anatomy of clubfoot. However, clubfoot has been treated by conservative methods for more than 40 years. Later, due to the 


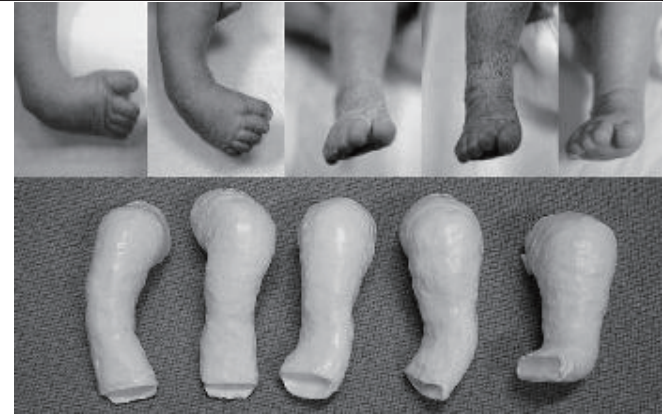

Fig. 5. Stages of casting intervention (Source and thanks to: [42]).

development of advanced surgical procedures, clubfoot was successfully corrected by "posteromedial release" techniques at the age of one year. Then, for the past decade, conservative treatment such as Ponseti method achieved high success rate due to the understanding of the functional anatomy of the clubfoot as compared to the surgical methods [2]. Recently, most of the studies stated that Ponseti method is considered as more effective method to correct the clubfoot without further complications such as stiffness and pain [55].

\section{Current conservative methods for clubfoot \\ 4.1. Ponseti method}

Over the past decade, conservative management has been wildly used to correct the clubfoot deformity than surgical management. Ponseti method is consists of weekly gentle manipulation and followed by application of serial long leg casting [56]. In this method, casting should be changed every 5 to 7 days (Fig. 5). Before the final casting, if there is still equinus deformity persists, Achilles tendon percutaneous tenotomy should be done to correct the equinus deformity fully. Approximately ninety percentages of the cases requires tenotomy. Then, the foot will be immobilized for 21 days with $60^{\circ}$ abduction and maximum dorsiflexion $[42,56,57]$. Once the clubfoot is corrected, the child needs to wear full-time foot abduction brace for twelve weeks ( 23 hours per day). After 3 months, foot abduction brace are used at night and nap time until the age of four to prevent the relapse of club foot. Foot abduction orthosis or brace are used after the foot achieves about $60^{\circ}-70^{\circ}$ abduction and $20^{\circ}$ dorsiflexion range of motion. The goal of treatment of Ponseti method aims to correct four basic deformities: ankle equinus, hindfoot varus, forefoot adductus and

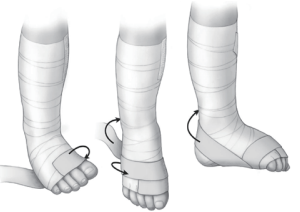

A

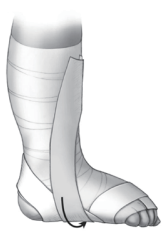

C
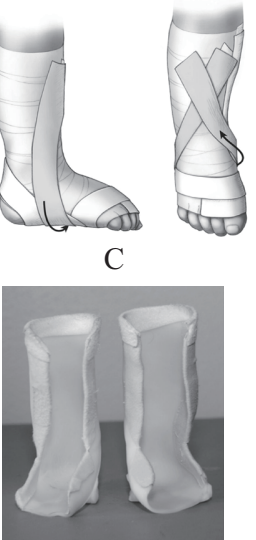

E
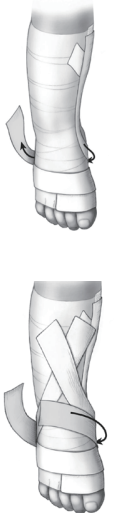

B
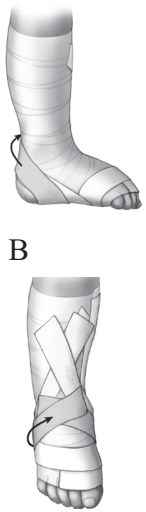

Fig. 6. A-D: Steps of taping techniques. E: Ankle foot orthosis (Source and thanks to: [58] - Picture is adapted and formatted).

cavus. Initially, during the application of the first casting, cavus deformity is corrected by supination of the forefoot with providing pressure in the first metatarsal head of the forefoot. Mostly, the cavus deformity correction will be achieved in the first casting. During the next 3 or 4 casting application, simultaneously adduction and varus, equinus deformity will be corrected by providing counter pressure on the talar head with positioning the foot in the abduction and external rotation $[42,57]$.

\subsection{French functional or physiotherapist method}

The principle of French functional conservative method stated that clubfoot deformity occurs due to the contracture of the following foot structures: tendon of the posterior tibialis muscles and fibrotic tissues, weakness of peroneus longus and peroneus previous muscles, and deviation of mid-tarsal joints. Therefore, this method is mainly focused on stretching of medial side of the foot. In this method, treatment techniques such as stretching, daily corrective manipulations have been used to correct the deformity. The corrected foot are maintained by elastic taping and splints until the next day of treatment as shown in Fig. 6 [58]. The total duration of treatment is $1-3$ months, and therapist sees the patients five days per week. Then, the 


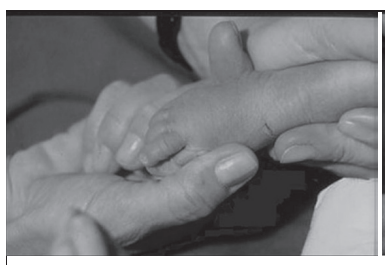

A. Correction of adducted deformities

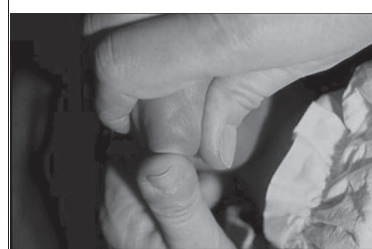

C. Correction of varus

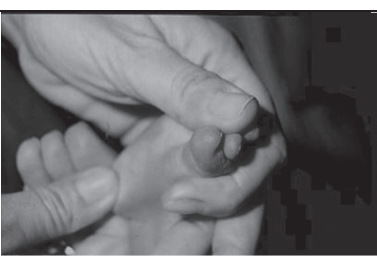

B. Correction of cavus

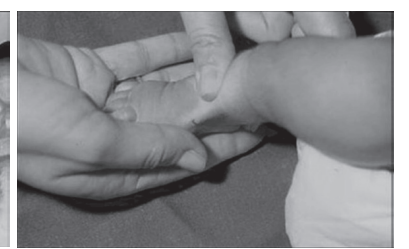

D. Correction of Equinus
Fig. 7. Manipulation of clubfoot by Copenhagen method (Thanks to [47]).

family members need to help the child to do the exercise regularly at home. This method has two phases of treatment: corrective phase and maintenance phase. Corrective phases of the treatments include calf massage, forefoot stretch, distraction, derotation, stimulation of evertors, hindfoot valgus, and dorsiflexion. In the maintenance phase, splints are used to maintain the correction [58].

\subsection{Copenhagen method}

In 1976, another conservative clubfoot treatment technique, Copenhagen method was developed in Copenhagen orthopaedic hospital. The following technique has been used to treat the clubfoot problems: flexion and manipulation, stimulation of muscles of the foot, using plaster of cast. These techniques need to be practiced daily until the foot become as 'normal' and it might be achieved in 6 weeks period of treatment [59]. The corrected foot are maintained by bandage instead of using braces until the child gets to start to walk. Also, the corrected clubfoot is inspected periodically until the skeletal maturity $[47,59]$. According to the modified Copenhagen method, to correct the clubfoot adduction, varus, and cavus deformities, the following principles of "correction rule" is applied in a sequential order: correcting the adducted deformity first, then other deformities such as cavus, varus, and equinus are performed.

The adducted deformity is corrected by holding hind foot by one hand, and the tibial epiphysis and cuboid bone should be between the index finger and thumb of the same hand. Subsequently, the forefoot adduction is corrected by distraction movement applied by the thumb of another hand on the first metatarsophalangeal joint (Fig. 7A). Cavus is corrected by supination of forefoot while performing the dorsiflexion motion at the first metatarsal area of the foot (Fig. 7B). The varus deformity is corrected by holding the heel of the feet (posterior side) by one hand, and pressure provided on the neck of the talus bone to push the inwards while thumb of the same hand used to give pressure on the calcaneal bone towards outside. At the same time, pressure is applied to the metatarsal bones (sole of the foot) by using another hand to obtain the everted position of the forefoot (Fig. 7C). Equinus deformity correction is achieved by gentle traction of Achilles tendon by one hand while performing dorsiflexion of the forefoot by another hand (Fig. 7D) [47,60]. Finally, lateral side of the muscles (Peroneal muscles and anterolateral area of the foot) will be stimulated by brush after the manipulation of the foot [47]. Once the clubfoot is corrected, Larsen Active T splint are used to maintain the foot until 7 to 8 months, after that it is used at night time. At the same time, this method recommends regularly exercises 5 times per day.

\section{Discussion}

Although there are a number of conservative method used to treat the clubfoot problems, the outcome varies from one method to another. The purpose of this review was aimed to provide the various method of conservative treatment and classification the of clubfoot severity to predict the outcome of the intervention. Previous studies have reported that clubfoot can be treated by less casting and duration by Ponseti method compared to other method to achieve the full correction of the clubfoot with good mobility of the foot [61]. The manipulation and casting techniques were described in both Kite method and Ponseti method, however the success rate varied about ten to eighty percentages in Kite method. Serial casting has been followed as stretching techniques in the both method to achieve normal and functional foot but it differs in their manipulation techniques. Forty two years of experience of Ponseti, he stated that he achieved ninety percentages of successful outcomes of clubfoot correction by practicing his own regime method. Ponseti method is mostly used in USA, some part of Europe and developing countries such as India and Bangladesh. Ponseti method is widely used in the developing and de- 
veloped counties, with the ninety percentages of successful correction rates, while those who used Kite method have stated that fifty percentages of the cases required surgical correction and around forty percentages persisted with residual deformity [33]. In contrast, one of the author reported that they achieved successful correction of clubfoot but they performed about ninety one percentages of percutaneous tenotomy of the Achilles tendon in their study [12]. Another study, Morcuende et al., stated that they performed Achilles tenotomy in the eighty six percentages of the cases to obtain the stated correction [65]. Other method, French functional physiotherapy method is also practiced in some centres of America and Europe. Few studies have reported that French functional physical therapy method is equally effective as the Ponseti method. In addition, one of the studies have reported that French functional physical therapy and Ponseti method achieved about ninety percentages of successful outcomes in the initial correction of the clubfoot. Though, thirty-seven percentage of relapses occurred in the Ponseti method and twenty nine percentages in the French functional physiotherapy method in the follow-up [66]. Very few studies reported and published about Copenhagen method as a conservative method for clubfoot correction. Peroneal muscle stimulation was performed in this method to strengthen the hypotonic muscles in addition to the physical manipulation and physical therapy exercises. In their studies, the author has reported that thirty-four percentages of feet did not require any surgeries and sixty percentage had posterior release, and two percentage had tenotomy of the Achilles tendon [47]. In conclusion, this literature review discussed several conservative methods of clubfoot treatment such as Kite method, Ponseti method, French physical therapy method, and Copenhagen method. After several decades of debates of surgical treatment for clubfoot, now-a-days, conservative management, especially Ponseti method, has been considered as best choice for clubfoot treatment in terms of low cost, low technology and effective outcome. However, further research is required to reduce the relapses rate by considering the combination approaches of casting, physical therapy, and stimulation of hypotonic muscles.

\section{Conflict of interest}

\section{The authors have no conflict of interest to report}

\section{References}

[1] Ponseti International Association. What is clubfoot? Re trieved from http://www.ponseti.info/what-is-clubfoot.html 2016.

[2] Foster A, Davis N. Congenital talipes equinovarus (clubfoot) Surgery. 2007; 25(4): 171-175.

[3] Seravalli V, Pierini A, Bianchi F, Giglio S, Vellucci FL Cariati E. Prevalence and prenatal ultrasound detection of clubfoot in a non-selected population: an analysis of 549,931 births in Tuscany. J Matern Fetal Neonatal Med. 2014; 11 $1-14$.

[4] Drvaric DM, Kuivila TE, Roberts JM. Congenital clubfoot. Etiology, pathoanatomy, pathogenesis, and the changing spectrum of early management. Orthop Clin North Am. 1989 20(4): 641-647.

[5] Herring JA. Tachdjian's pediatric orthopaedics: From the texas scottish rite hospital. $5^{\text {th }}$ ed. Philadelphia: Elsevier 2013.

[6] Dobbs MB, Gurnett CA. Update on Clubfoot: Etiology an Treatment. Clin Orthop Relat Res. 2009; 467(5): 1146-1153.

[7] Hui C, Joughin E, Nettel-Aguirre A, Goldstein S, Harder J, Kiefer G, Parsons D, Brauer C, Howard J. Can J Surg. 2014. 57(4): 247-253

[8] Turco VJ. Clubfoot. New York: Churchill Livingstone; 1981.

[9] Kite J. The Clubfoot. New York: Grune and Stratton; 1964.

[10] Su Y, Nan G. Manipulation and brace fixing for the treatment of congenital clubfoot in newborns and infants. BMC Muscu loskelet Disord. 2014; 15(363): 1-5.

[11] Yang JP, De DG. Early manual correction plus series cast im mobilization for treatment of congenital club foot. Chin J Pe diatr Surg. 2003; 24: 205-207.

[12] Herzenberg JE, Radler C, Bor N. Ponseti versus traditiona methods of casting for idiopathic clubfoot. J Pediatr Orthop. 2002; 22(4): 517-521.

[13] Ponseti IV. Treatment of congenital club foot. J Bone Join Surg Am. 1992; 174(3): 448-454.

[14] Crawford AH, Gupta AK. Clubfoot controversies: complica tions and causes for failure. Instr Course Lect. 1996; 45: 339 346.

[15] Beals RK. Club foot in the Maori: a genetic study of 50 kin dreds. N Z Med J. 1978; 88: 144-146.

[16] Mittal RL, Sekhon AS, Singh G, Thakral H. The prevalence of congenital orthopaedic anomalies in a rural community. In Orthop. 1993; 17(1): 11-12.

[17] Shiels WE, Coley, BD, Kean J, Adler BH. Focused dynamic sonographic examination of the congenital clubfoot. Pediatr Radiol. 2007; 37: 1118-1124.

[18] Bhargava SK, Tandon A, Prakash M, Arora SS, Bhatt S, Bhar gava S. Sonographic Evaluation of Clubfoot. JIMSA. 2013 26(1): 9-13.

[19] Dobbs MB, Gurnett CA. Genetics of Clubfoot. J Pediatr Or thop. 2012; B21(1): 7-9.

[20] Chung CS, Nemechek RW, Larsen IJ, Ching GH. Genetic and epidemiological studies of clubfoot in Hawaii. General and medical considerations. Hum Hered. 1969; 19: 321-342.

[21] Gadhok K, Belthur MV, Aroojis AJ, Cook T, Oprescu F Ranade AS, Morcuende JA. Qualitative assessment of the challenges to the treatment of idiopathic clubfoot by the Ponseti method in urban India. Iowa Orthop J. 2012; 32: 135-140.

[22] Alberman ED. The causes of congenital club foot. Arch Dis Child. 1965; 40: 548-554

[23] Cartlidge I. Observations on the epidemiology of club foot in 
Polynesian and Caucasian populations. J Med Genet. 1984; 21(4): 290-292.

[24] Wynne-Davies R. Family studies and the cause of congenital club foot. J Bone Joint Surg Br. 1964; 46B: 445-463.

25] Lochmiller C, Johnston D, Scott A, Risman M, Hecht JT. Genetic Epidemiology study of idiopathic talipes equinovarus. Am J Med Genet. 1998; 79: 90-96.

[26] Bernhardt DB. Prenatal and Postnatal Growth and Development of the Foot and Ankle. Phys Ther. 1988; 68: 1831-1839.

[27] Siapkara A, Duncan R. Congenital talipes equinovarus: a review of current management. J Bone Joint Surg Br. 2007; 89(8): 995-1000.

[28] Jeevan RR, Vijayaragavanb E, Kirubac A. 3 dimensional modeling of an ankle foot orthosis for clubfoot deformity. Int J of Biomed Res. 2011; 2(3): 171-180.

[29] Wallander HM. Congenital clubfoot. Aspects on epidemiology, residual deformity and patient reported outcome. Acta Orthop. 2010; 339(81 Suppl): 1-25.

[30] Irani RN, Sherman MS. The pathological anatomy of club foot. J Bone Joint Surg Am. 1963; 45(1): 45-52.

[31] Pirani S, Zeznik L, Hodges D. Magnetic resonance imaging study of the congenital clubfoot treated with the Ponseti method. J Pediatr Orthop. 2001; 21(6): 719-726.

32] Riegger CL. Anatomy of the Ankle. Phys Ther. 1988; 68: 1802-1814.

[33] Maranho DA, Volpon JB. Congenital Clubfoot. Acta Ortop Bras. 2011; 19(3): 163-169.

[34] Dimeglio A, Bensahel H, Souchet P, Mazeau P, Bonnet F. Classification of clubfoot. J Pediatr Orthop. 1995; 4(2): 129. 136.

35] Kruse L, Gurnett CA, Hootnick D, Dobbs M. Magnetic Resonance Angiography in Clubfoot and Vertical Talus A Feasibility Study. Clin Orthop Relat Res. 2009; 467(5): 1250-1255.

[36] Gray DH, Katz JM. A histochemical study of muscle in clubfoot. J Bone Joint Surg Br. 1981; 63B: 17-423.

37] Gibbons PJ, Gray K. Update on clubfoot. J Paediatr Child Health. 2013; 49(3): E434-E437.

38] Gordon N. Arthrogryposis multiplex congenita. Brain Dev. 1998; 20(7): 507-511.

[39] Nguyen MC, Nhi HM, Nam VQD, Thanh DV, Romitti P, Morcuende JA. Descriptive Epidemiology of Clubfoot in Vietnam: A Clinic-Based Study. Iowa Orthop J. 2012; 32: 120-124.

[40] Carroll NC. Clubfoot in the twentieth century: where we were and where we may be going in the twenty-first century. J Pediatr Orthop B. 2012; 21(1): 1-6.

[41] Chu A, Labar A, Sala D, van Bosse H, Lehman W. Clubfoot classification: correlation with Ponseti cast treatment. J Pediatr Orthop. 2010; 30: 695-699.

42] Bergerault F, Fournier J, Bonnard C. Idiopathic congenital clubfoot: Initial treatment. Orthop Traumatol Sur. 2013; 99(1 Suppl): S150-159.

[43] Joseph B, Robb J, Loder RT, Ian Torode. Paediatric Orthopaedic Diagnosis: Asking the Right Questions. India: Springer; 2015.

[44] Hefti F. Pediatric Orthopedics in Practice. Germany: Springer-Verlag Berlin Heidelberg; 2007.

[45] Wainwright AM, Auld T, Benson MK, Theologis TN. The classification of congenital talipes equinovarus. J Bone Joint Surg Br. 2002; 84-B: 1020-1024.

[46] Matanovic DD, Vukasinovic ZS, Zivkovic ZM, Spasovski DV, Bascarevic ZL, Slavkovic NS. Physical treatment of foot deformities in childhood. Acta chir lugosl. 2011; 58(3): 113 116.

[47] Utrilla-Rodríguez EM, Martínez-Canavete MG, Conejero Casares PA. Conservative Treatment of clubfoot using modified Copenhagen method. Pediatr Phys Ther. 2012; 24(1): 51 56.

[48] Kite JH. Some suggestions on the treatment of clubfoot by cast. J Bone Joint Surg. 1963; 45: 406-412.

[49] Kite JH. Non-operative treatment of congenital clubfoot. Clin Orthop. 1972; 84: 29-38.

[50] Weber A, Jaakola E, Haddon T. Current concepts in the management of clubfoot deformity: The ponseti method; 2004. http://www.podiatryinstitute.com/pdfs/Update_2004/2004_ 20.pdf.

[51] Karski T, Wosko I. Experience in the conservative treatmen of congenital clubfoot in newborns and infants. J Pediatr Orthop. 1989; 9(2): 134-136.

[52] Aronson J, Puskarich CL. Deformity and disability from treated clubfoot. J Pediatr Orthop. 1990; 10(1): 109-119.

[53] Zimbler S. Nonoperative management of the equinovarus foot: long-term results. In: The Clubfoot. Simons GW, editors. Newyork: Springer Verlag; 1994; 191-193.

[54] Clubfoot. 2015. http://globalclubfoot.com/clubfoot/history-of -clubfoot-management/.

[55] Laaveg SJ, Ponseti IV. Long-term results of treatment of con genital clubfoot. J Bone Joint Surg. 1980; 62-A: 23-31.

[56] Lara RCR, Montesi Neto DJC, Prado FR, Barretoc AP Treatment of idiopathic congenital clubfoot using the Ponset method: ten years of experience. Revista Brasileira de Ortopedia. 2013; 48(4): 362-367.

[57] Ponseti IV. Congenital clubfoot: fundamentals of treatment Oxford: Oxford University Press; 1996.

[58] Steinman S, Richards BS, Faulks S, Kaipus K. A compari son of two nonoperative methods of idiopathic clubfoot cor rection: the Ponseti method and the French functional (phys iotherapy) method. Surgical technique 2009; 91(2 Suppl) S299-312.

[59] Ward S, Shelton H. Maternal-child nursing care optimizing outcomes for mothers, Children 2nd Edition; 2015.

[60] Aurell Y, Andriesse H, Johansson A, Jonsson K. Ultrasound assessment of early clubfoot treatment: a comparison of the Ponseti method and a modified Copenhagen method. J Pediatr Orthop B. 2005; 14: 347-357.

[61] Sanghvi AV, Mittal VK. Conservative management of idio pathic clubfoot: Kite versus Ponseti method. J Orthop Surg (Hong Kong). 2009; 17(1): 67-71.

[62] Global HELP Organization. Clubfoot: Ponseti Management Edited by Staheli L, 2009. Retrieved from http://www.globalhelp.org/publications/books/help_cfponseti.pdf.

[63] Meena S, Sharma P, Gangary SK, Lohia LK. Congenital club foot. J Orthop Allied Sci. 2014; 2: 34-39.

[64] Dimeglio A, Bensahel H, Souchet P, Mazeau P, Bonnet F Classification of clubfoot. J Pediatr Orthop. 1995; B4: 129-36.

[65] Morcuende JA, Dolan LA, Dietz FR, Ponseti IV. Radical re duction in the rate of extensive corrective surgery for clubfoot using the Ponseti method. Pediatrics. 2004; 113: 376-380.

[66] Faulks S, Richards BS. Clubfoot treatment: Ponseti and French functional methods are equally effective. Clin Orthop Relat Res. 2009; 467(5): 1278-1282.

[67] Global HELP Organization. Clubfoot: Ponseti clubfoot Management Edited by Staheli L, 2008. Retrieved from https:// global-help.org/publications/books/help_ponsetiuganda.pdf. 